\title{
SEVERE ACCIDENTAL FLAYING
}

\author{
A Plea for Initial Conservatism \\ P. S. London and Ruscoe Clarke, Birmingham, England
}

From the Birmingham Accident Hospital

Severe flaying injuries are uncommon but are well recognised hazards of road and factory accidents. Their nature and cause have been described by Slack (1952) and Prendiville and Lewis (1955). Typically, the injury is due to a rolling action, usually produced by a large balloon tyre or a moving belt. The skin and subcutaneous tissues are sheared off the deep fascia and, although this may be the only damage, usually the skin splits and the limb becomes unwrapped. The deep fascia is shredded, and mobile muscular masses and neurovascular bundles are split away from each other while often remaining individually intact (Fig. 1). When the impact falls on muscles that are attached to bone these are commonly torn loose
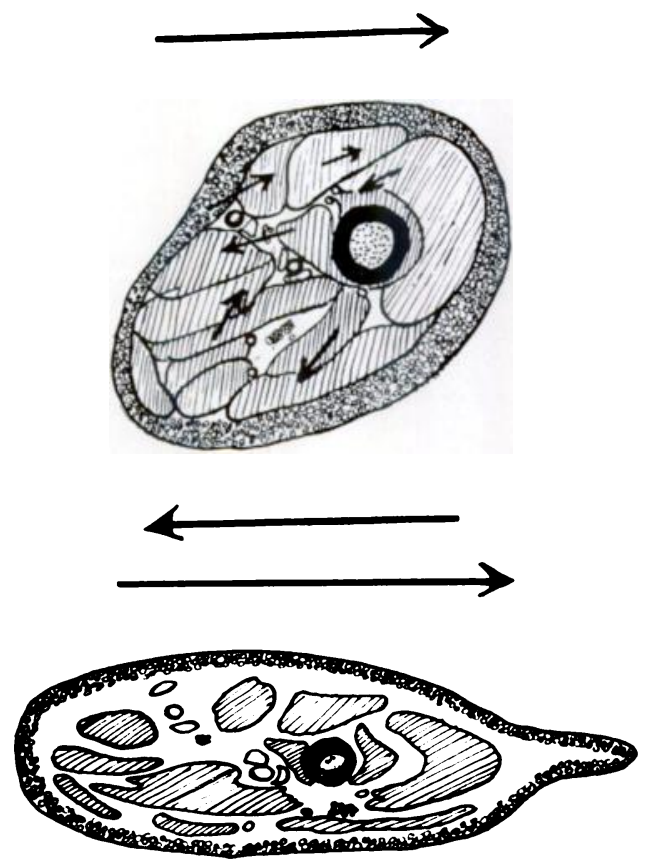

FIG. 1

The effect of shearing and crushing forces on the connective tissue planes between the formed structures of a limb. and more seriously damaged. When the hands and feet are affected the details of the process are different.

The most important part of this lesion is the widespread undermining and stripping of skin and subcutaneous tissues from the deeper structures, which do not usually suffer serious damage. The survival of the skin will depend upon the damage inflicted on its blood supply by forces that split, strip and crush; the outstanding feature of these injuries is that the damage varies greatly and is unpredictable. Some thrombosis is likely and, even though negligible at first, may increase later and cause death of tissue by infarction. Infarction may be visible in injured veins from the beginning and deprive the overlying skin of the channels through which to acquire a circulation, so that it would not survive if used as a Wolfe graft.

Treatment is the main bone of contention. Broadly, it may follow one of three general lines: 1) As much as possible of the flaps is replaced at the first operation and excision deferred until dead skin has been clearly defined (Graham 1939, Stevenson 1941, Entin 1955). 2) The subcutaneous fat is removed and the skin alone replaced as a type of Wolfe graft, either free or still attached (Farmer 1939, Homans 1939, Mathewson and Gerber 1947, Mulholland and Mahoney 1952, Slack 1952). 3) The flaps are cut away and the raw surface is grafted at once (Schjelderup 1947, Prendiville and Lewis 1955, Innis 1957).

The balance of published opinion is tilted steeply against the first method and the reasons given appear to carry conviction, namely that the undermined skin dies and that ensuing infection prejudices the success of early grafting and delays healing. We are convinced that 


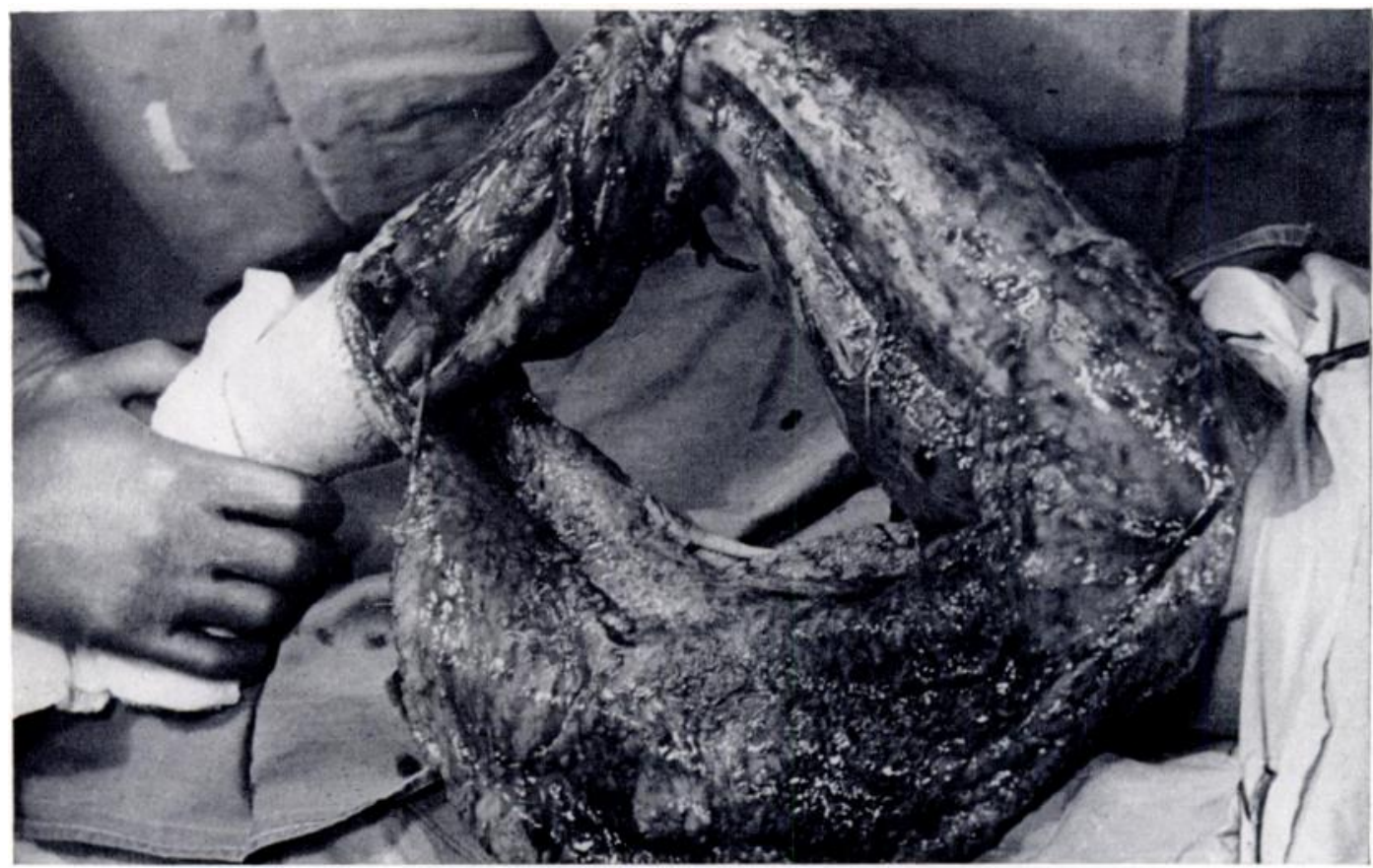

Fig. 2

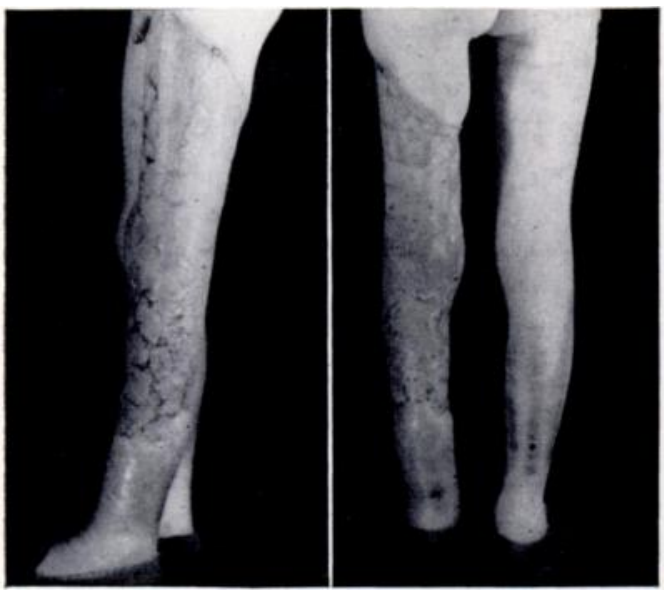

FIG. 3

Figs. 2 to 5

Case 1-Run-over accident. Figure 2-The boy's leg on admission. Practically all the flayed skin died. Figure 3-Nine weeks after the injury. Figure 4Eighteen months after the injury the boy can run, jump, swim and win races. Figure 5-The clinical record.

VOL. 41 B, NO. 4, NOVEMBER 1959

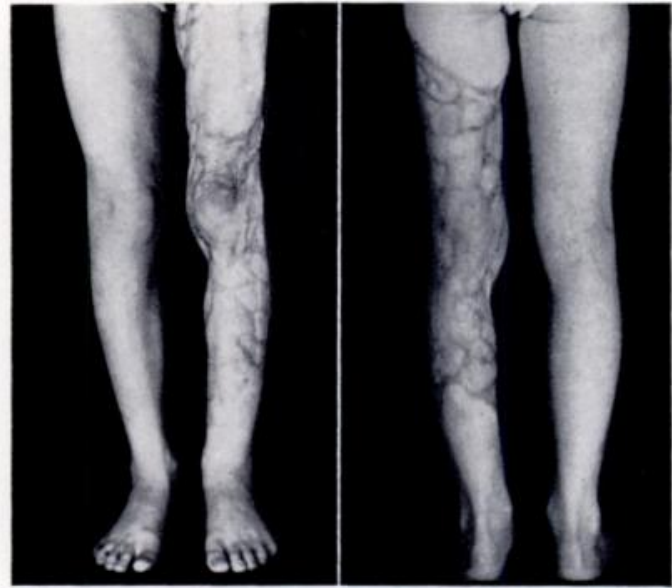

FIG. 4

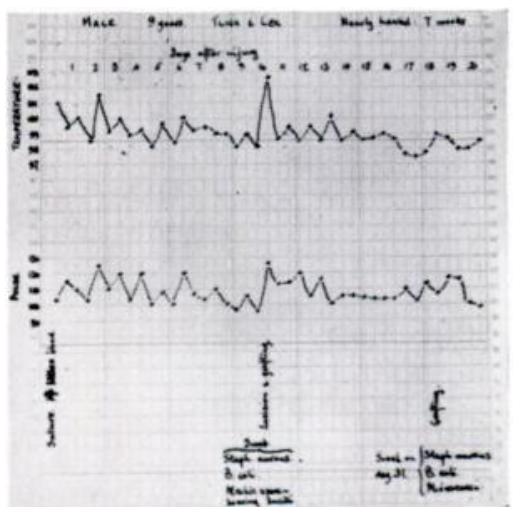

FIG. 5 
the case against the conservative approach has been overstated. From our experience of over a dozen injuries in which about half or more of a limb has been flayed we are satisfied that sewing back the flaps can have important advantages and that the risks of serious infection are much less than has been suggested, provided that the wound is properly dressed and that excision of the dead skin at the most favourable time is followed immediately by grafting.

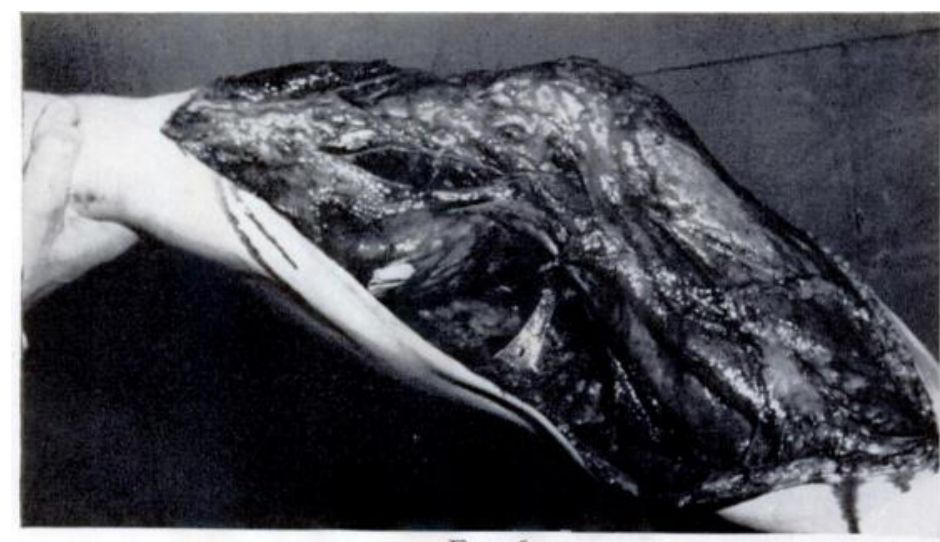

FIG. 6

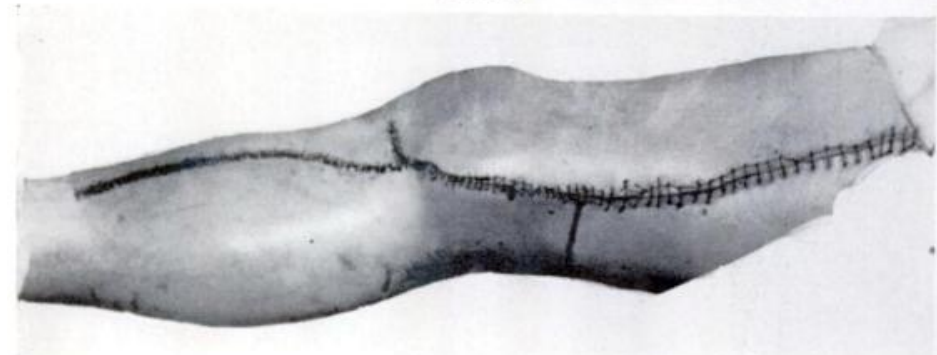

FIG. 7

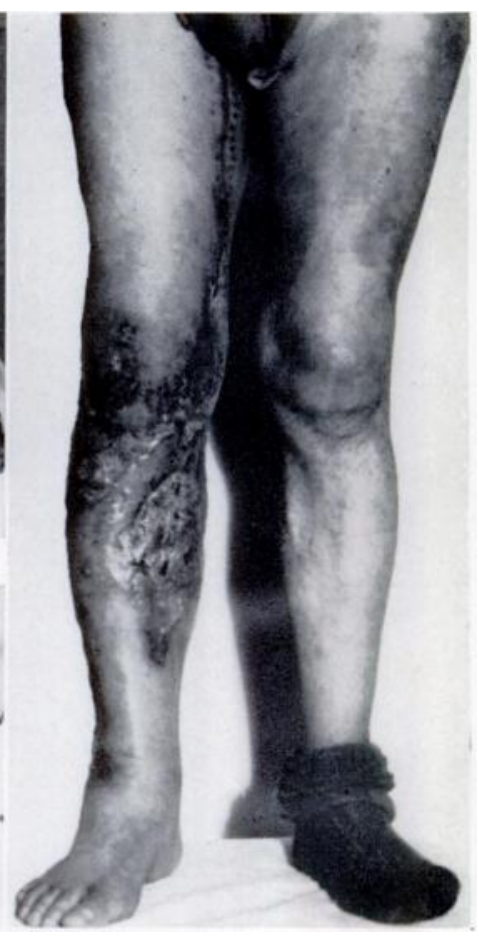

FIG. 8

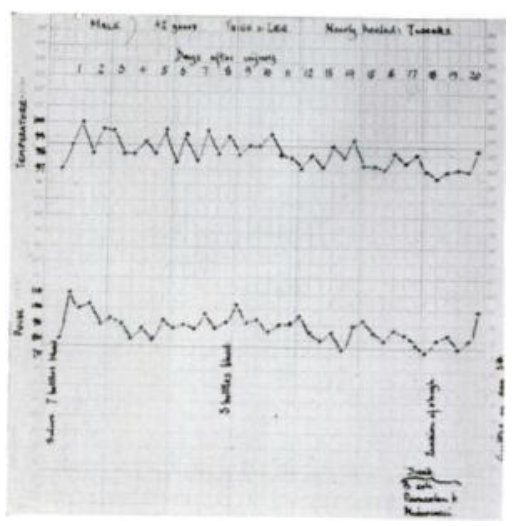

Figs. 6 to 9

Case 2--Run-over accident. Figure 6-On admission. Figure 7-All the flayed skin was sewn back with great difficulty owing to the swelling of the limb. The sutures are fine and closely set. Figure 8-Ten weeks after injury the leg is healed. Even in the most damaged places skin loss was only partial. Figure 9The clinical record.

Our case rests mainly on our experience that not all the undermined skin dies and that it is not possible to foretell its fate with accuracy. Immediate complete suture restores the tension of the surrounding skin to something like normal and reduces to the least the area of skin that will die. It is also a simpler operation than extensive primary grafting. Finally, on a number of occasions and in important situations over fractures or joints, necrosis has been 


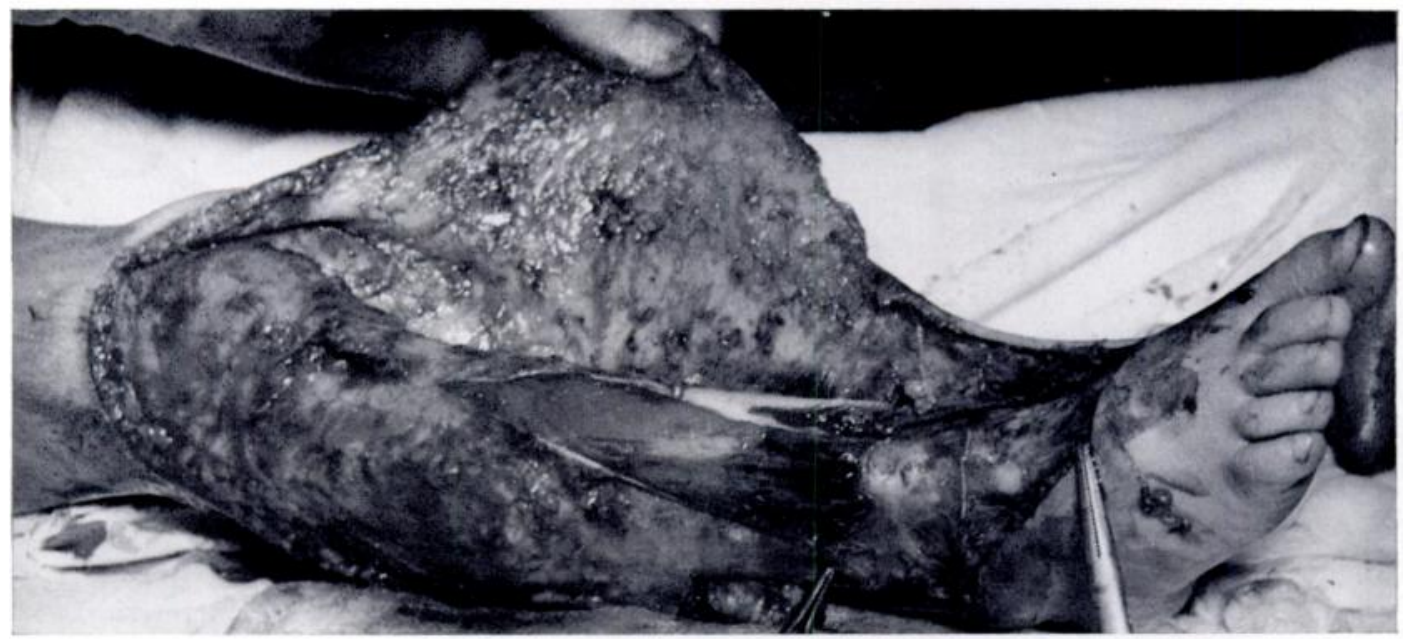

FIG. 10

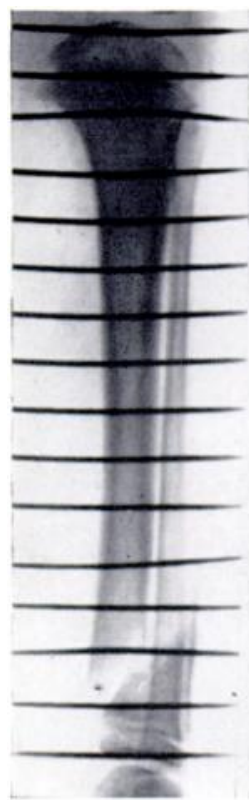

Fig. 11

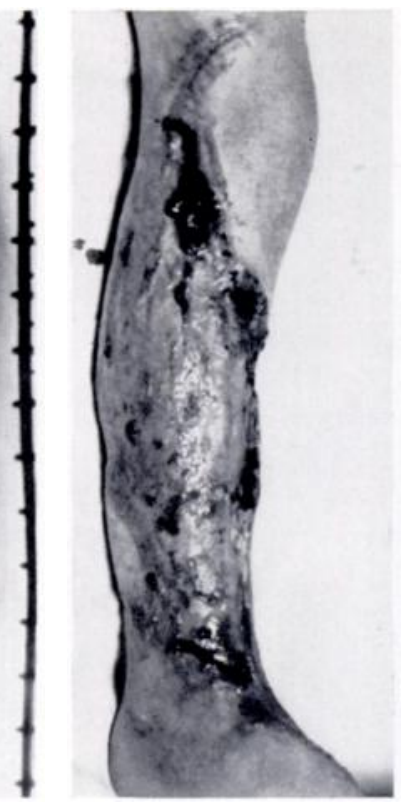

FIG. 12

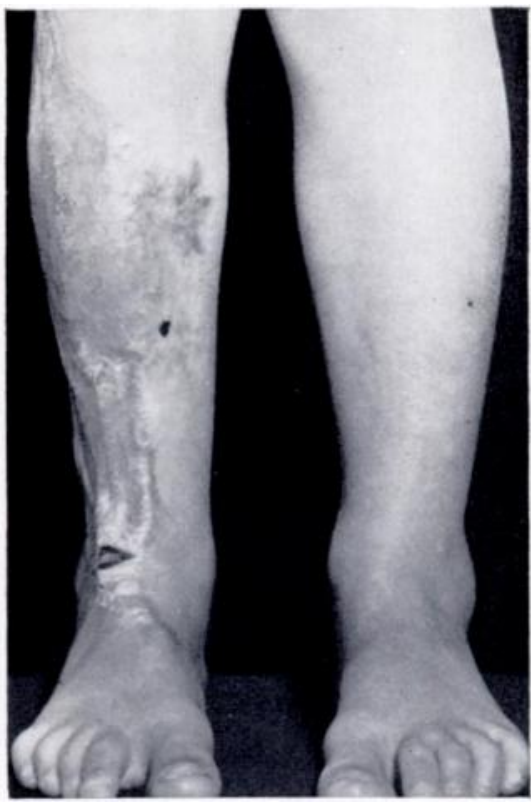

FIG. 13
Figs. 10 to 14

Case 3-Run-over accident. Figure 10-The appearance on admission. The skin over the unstable fracture (Fig. 11) and the shin survived. Figure 12-Four weeks after the injury. One month later the leg was healed. Figure 13-Eighteen weeks after the injury. There is a crack in the hypertrophic scar at the ankle. Figure $14-$ The clinical record.

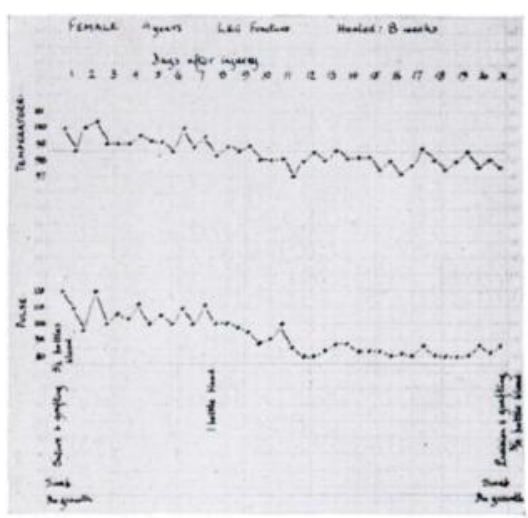

Fig. 14 


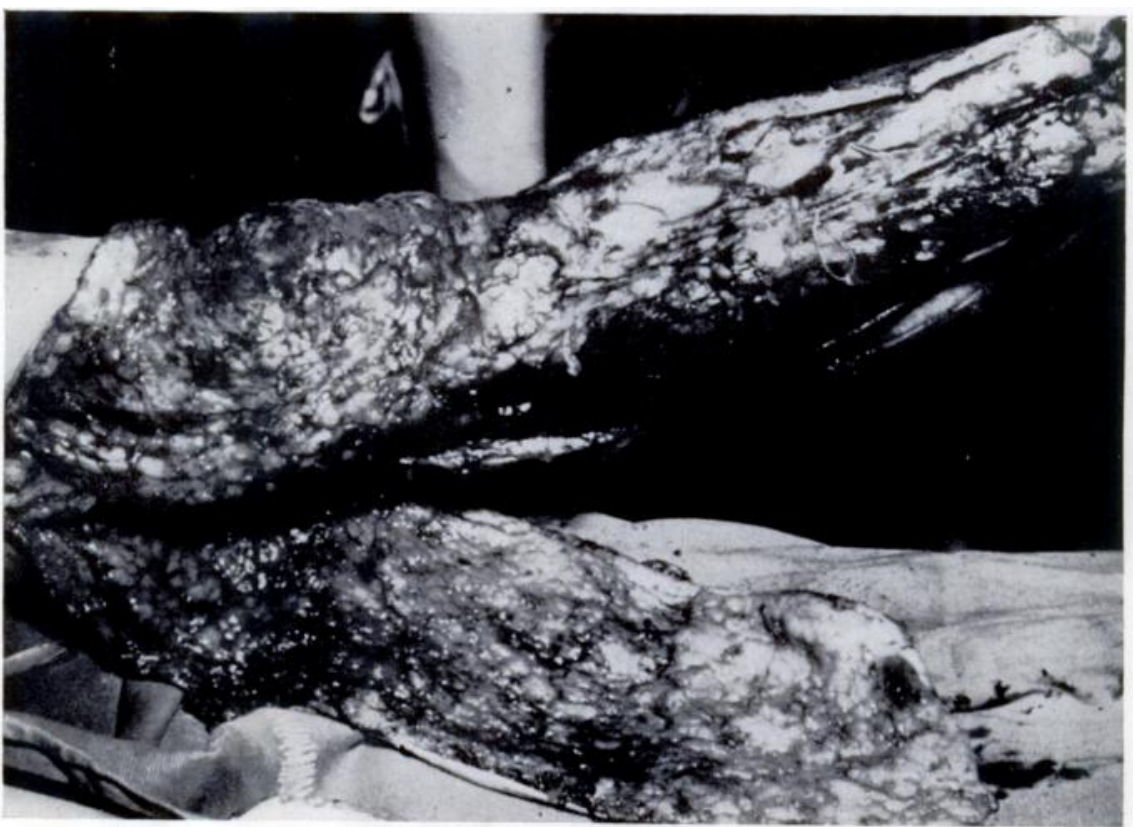

FIG. 15

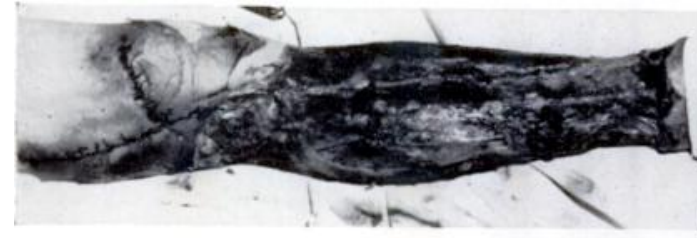

Fig. 16

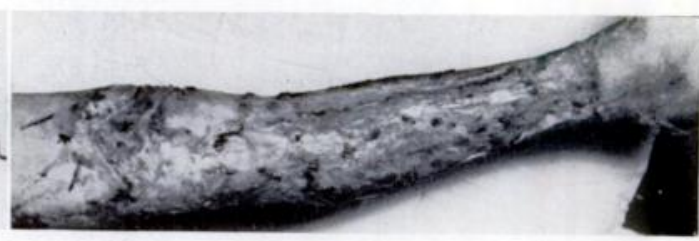

FIG. 17

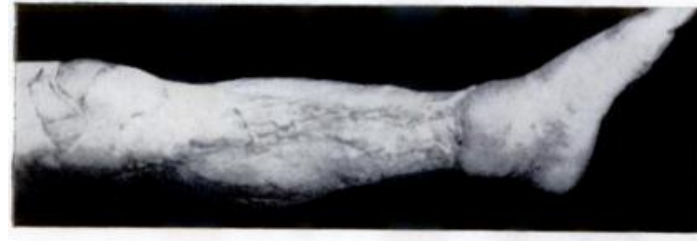

Fig. 18

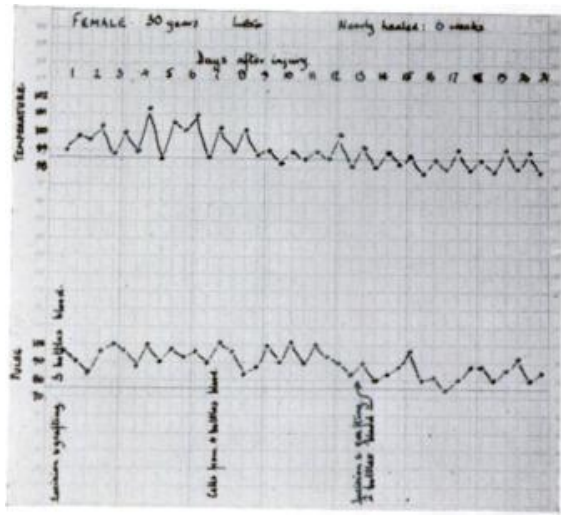

Fig. 20

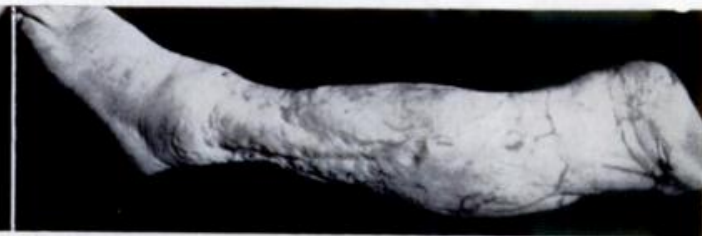

FIG. 19
Figs. 15 to 20

Case 4-Run-over accident. Figure 15-The base of the flap was retained to cover the knee: the rest of the leg was grafted. Figures 16 and 17-Two weeks after injury the primary grafts are satisfactory but some of the retained skin has died. Figures 18 and 19-The limb eleven months after injury. Figure 20-The clinical record. 
confined to surface layers with survival of the subcutaneous fat, so that when the slough was excised the depths of the wound were not disturbed.

Figures 2 to 5 (Case 1) show a limb in which hardly any of the separated skin survived. Sewing it back shortened the operation in a child that had lost much blood. Nevertheless. except for a few tiny scabs the limb was healed within two months and the residual scarring no longer caused complaint once the boy found that he could win races against his fellows.

Figures 6 to 9 (Case 2) show a similar injury to that of Case 1, with survival of most of

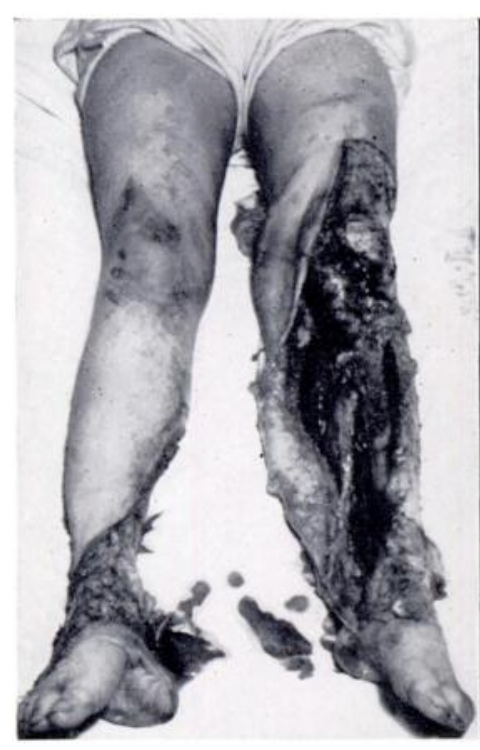

FIG. 21

FIGS. 21 to 25

Case 5-Run-over accident. Figure 21-The appearance on admission. Notice the injury to the right foot. The skin below the right heel and around the left ankle survived. Figures 22, 23 and 24-Nearly six years later. Figure 25-The clinical record.

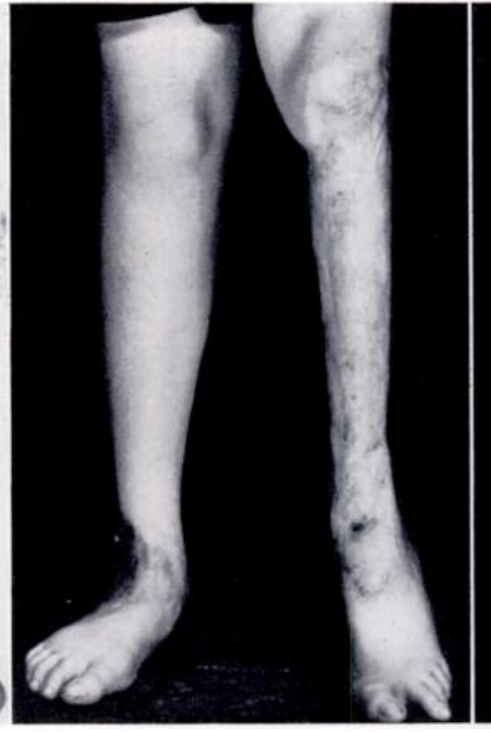

FIG. 22

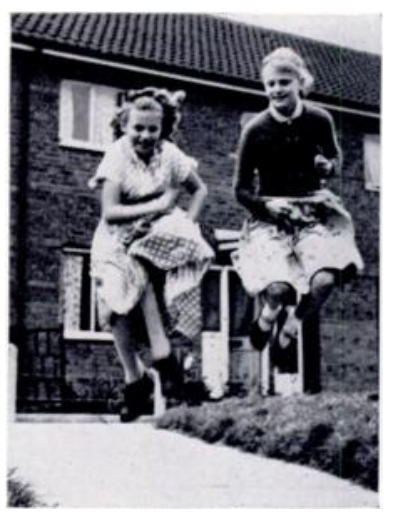

FIG. 24

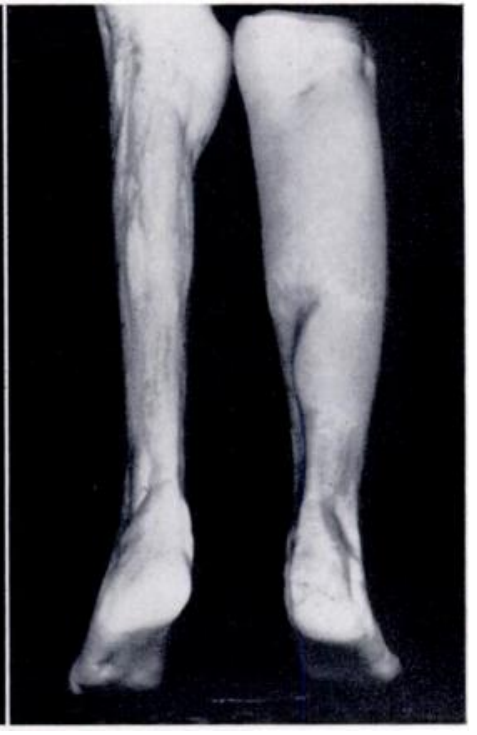

FIG. 23

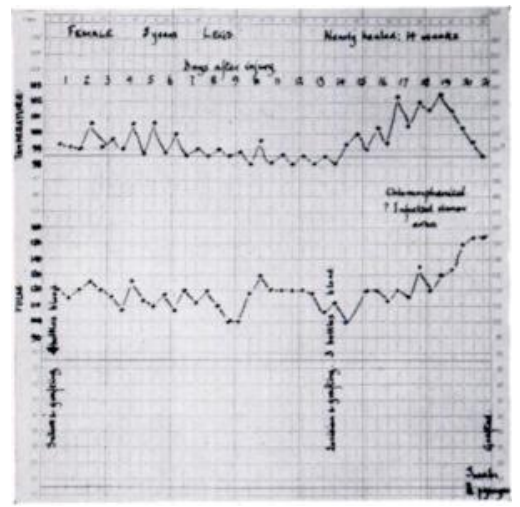

FIG. 25

the undermined skin. The knee retained over half its normal covering of skin and the limb had practically healed within seven weeks of injury.

The flap shown in Figures 10 to 14 (Case 3) was based on a line from the inner side of the foot to the inner side of the knee. Had all the undermined skin been removed (Innis 1957) some of the tibia, including the fracture, would have been bared of all soft tissue, but, as it was, enough of the flap survived to leave the knee and shin covered by normal skin. There was no evidence of infection when the dressing was changed at three weeks, and the limb was healed within two months. The fracture united within the same period, having been held in position by a single screw supplemented by a plaster case. 
With the single-ended flap shown in Figures 15 to 20 (Case 4) there was no doubt that much of it would die, but it was hoped that enough could be kept to cover the knee. The rest of the area was grafted immediately. Nearly all the retained part of the flap survived, and the patient left hospital within six weeks of injury, walking and with the wound nearly healed.

In Case 5 (Figs. 21 to 25) little of the undermined skin survived but what did was of great value. On the right foot the skin of the point of the heel died and the grafted area here gave trouble, but the skin on the main weight-bearing surface survived completely. On the other leg the equinus deformity was later safely corrected by operation through skin that had

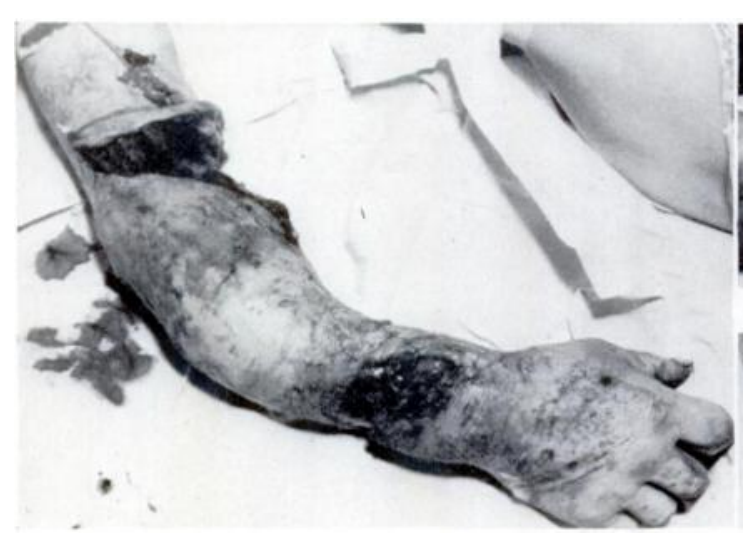

FIG. 26

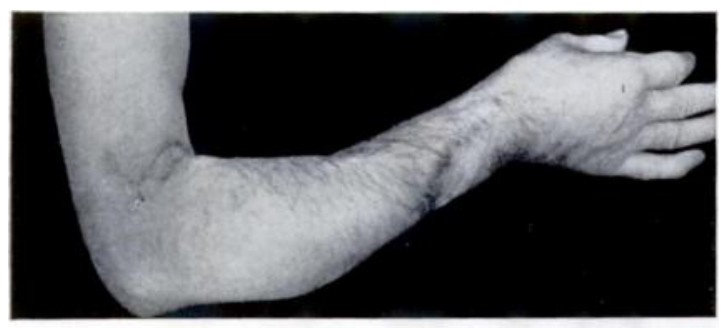

FIG. 29

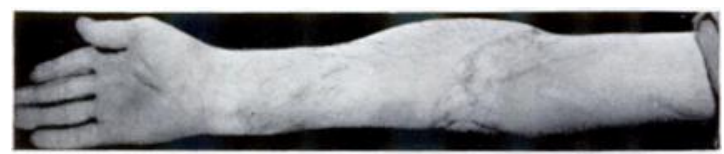

FIG. 30

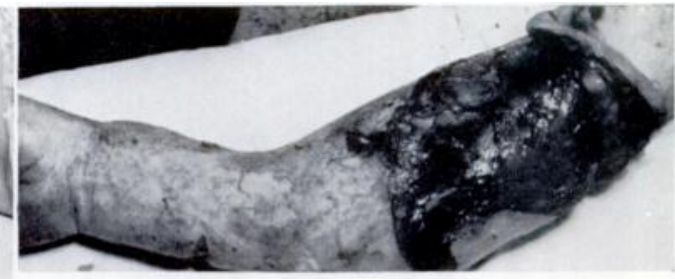

FIG. 27

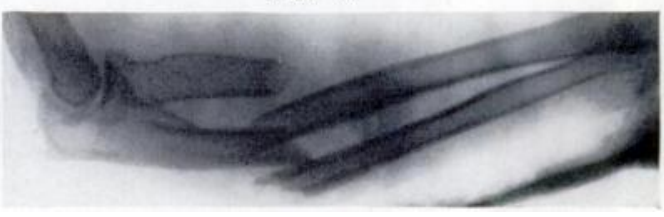

FIG. 28

Case 6-Arm caught by a machine belt. Figures 26 and 27-The state on admission. The biceps and brachialis were badly torn near their insertions. Figure 28 - The underlying fracture. Figures 29 and 30 -Sixteen weeks after the wound had been closed by suture and grafting. Figure $31-$ The clinical record.

survived undermining. This child also illustrates the more serious nature of the complications when the lower part of the leg and foot suffer injury of this type; damage to the ankle joint was only partly responsible for the equinus deformity as there was also ischaemic contracture of the calf muscles.

Cases 6 to 8 (Figs. 26 to 41 ) illustrate other injuries with survival of most of the stripped skin and also show that skin that has died can provide effectual cover for the tissues beneath. If the dead "dressing" be removed within three weeks or so these deeper tissues will often be found to be suitable for split-skin grafting without the further delay that allows increasing fibrosis. Case 9 (Figs. 42 to 48) shows that even though the skin dies the subcutaneous tissue 
of a flap may survive. Here an underlying fracture remained safely covered throughout the process of demarcation of dead skin, excision of slough and grafting.

In the bigger wounds of this kind, and when primary excision would leave a fracture or joint open to the surface without the possibility of cover by adjacent deep tissue, the advantages of initial conservatism are certainly not outweighed by the risks or effects of infection. Minor infection has been common but rarely has it affected treatment or delayed recovery to any important extent. Our patients did not spend any longer in hospital than those with wounds of comparable severity treated by immediate grafting (Innis 1957).

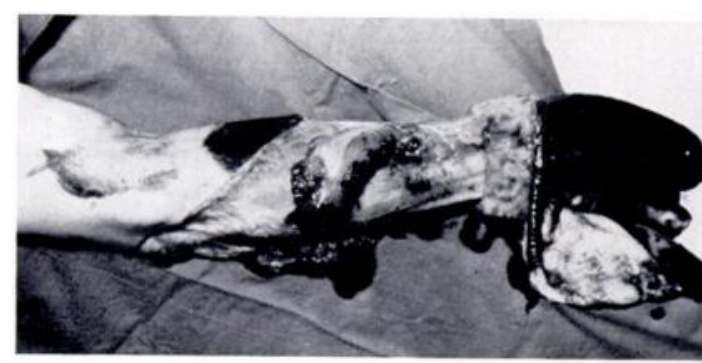

FIG. 32

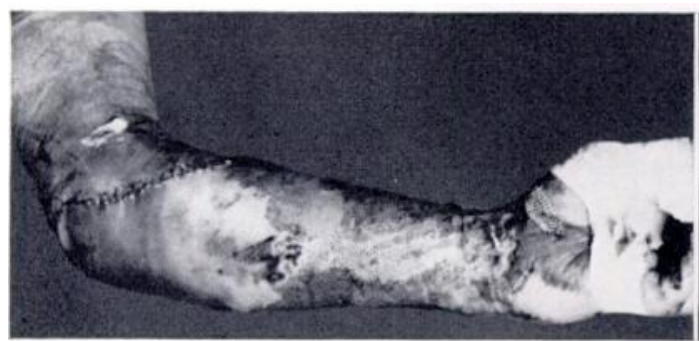

FIG. 34

Figs. 32 to 36

Case 7-Arm caught in machinery. Figure 32-On admission the flexor carpi radialis muscle was found torn from its origin and there was an open fracture of the ulna (Fig. 33). The wound was closed by suture. Figure 34-Seven days later. Figure 35Five months after injury the patient played the piano, despite limitation of finger flexion and a radio-ulnar synostosis, and declined further treatment. Figure 36-The clinical record.

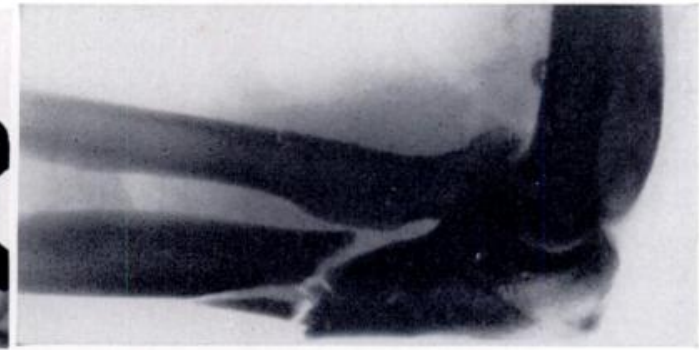

FIG. 33

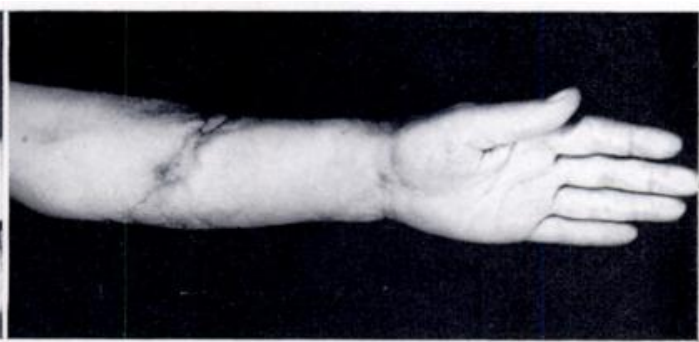

FIG. 35

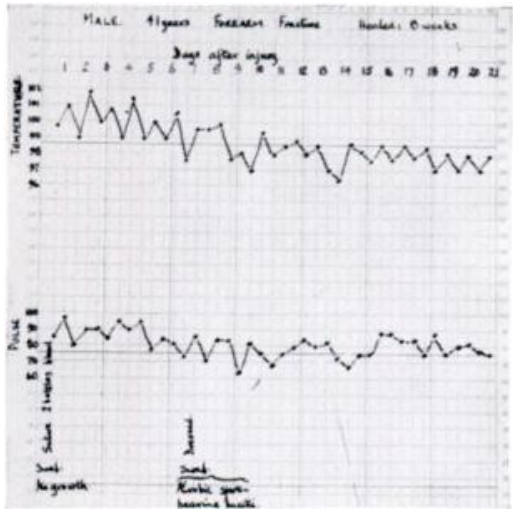

Fig. 36

Much of the argument against conserving injured skin has been based on patients with neglected infection and unnecessary delay in grafting after sloughs had been removed. The correct timing of dressings and surgical treatment is the key to reducing this delay and its complications.

Sudden fever, continuing or recurrent pain, smell and haemorrhage are indications for inspecting the wound without delay. When there are fractures the fate of the skin is important, and if there is serious doubt about its survival it should be inspected after five to seven days, 
when, in the absence of infection. it is still possible to restore skin cover by suitable grafting before the wound becomes contaminated from without. If it is thought that most of the skin will survive it need not be inspected for about two weeks, by which time sloughs are usually ready to be excised. This should be done when the skin is black and a line of demarcation

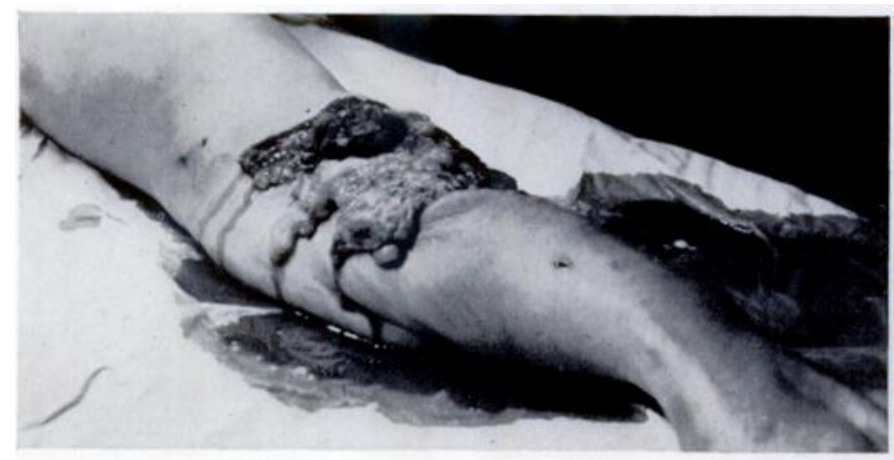

FIG. 37

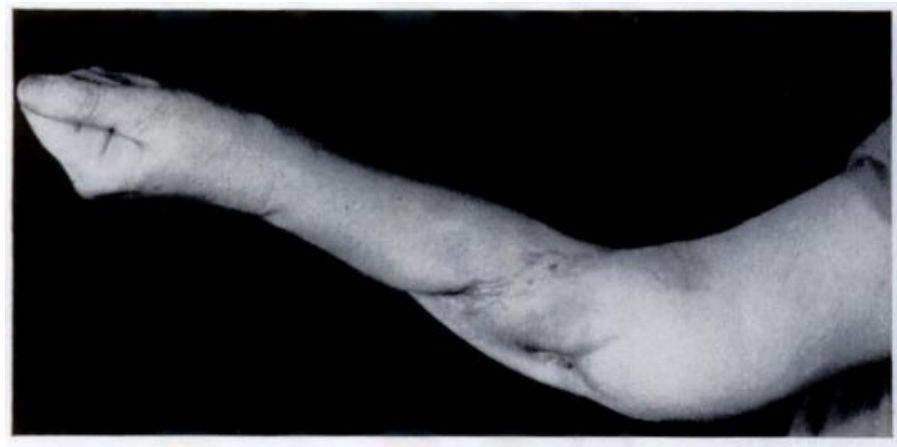

FIG. 39

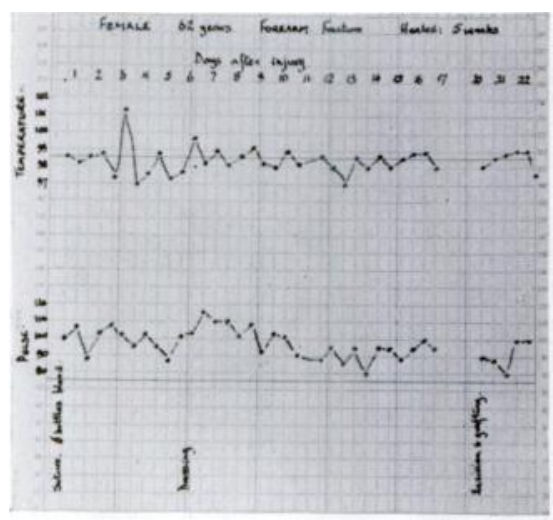

Fig. 41

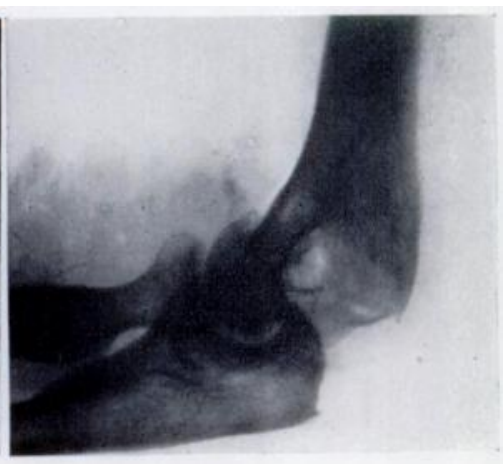

FiG. 38

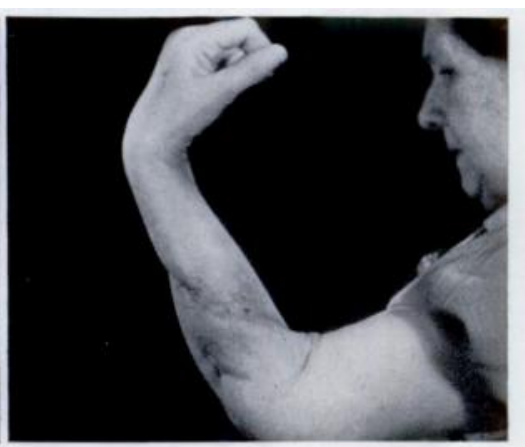

FIG. 40

Figs. 37 to 41

Case 8-Run-over accident. Figures 37 and 38On admission. The injury to the elbow joint was open. The wound was closed by suture. Figures 39 and 40 -Eight weeks later. Figure $41-$ The clinical record.

has formed. Areas of wet gangrene should be excised as soon as they are found. Although wet sloughs are not always clearly outlined there is a plane of ready cleavage between the living and dead tissues which is a reliable guide to the limits of excision.

For grafting large raw surfaces an electric or pneumatic dermatome enables skin of constant thickness to be obtained rapidly and safely without special skill. 
Unless the appropriate facilities are available, victims of serious flaying injuries should be transferred to a suitably equipped hospital within forty-eight hours; this is of particular importance if injured skin has been replaced or if it has been excised and the limb dressed without grafting.

The clinical records of the cases shown summarise a number of relevant details, including the temperature and pulse. Bacteriological investigation was far from complete, but it can be seen that fever and the culture of pathogenic organisms did not necessarily go together and that in many patients the fever subsided before all dead tissue had been removed. (In no patient was there any serious fever after about three weeks.)

The factors that may promote the survival of injured and undermined skin and reduce the risk and effect of infection are: 1) prompt treatment, 2) adequate transfusion, 3) thorough cleansing, 4) careful handling of injured tissue, 5) careful dressing technique, and 6) appropriate after-care. Operations urgently required to stop bleeding can be carried out safely with adequate blood transfusion.

Wounds of this nature are liable to bacterial contamination from the time of their infliction, but prompt, thorough cleansing, followed by careful surgical toilet, reduces the risk of established infection, and immediate closure does much to prevent further contamination. The longer such a wound remains open the more difficult it is to close because of swelling of both muscles and skin. The laxity of the retracted skin enables it to undergo vascular engorgement, which is aggravated by kinking or twisting. Therefore, flaps should be laid gently in place as soon as possible and supported by firm, even pressure until operation. Vascular engorgement reduces the extensibility of the skin and makes it difficult to restore the flaps to their normal area; with the muscles swollen as well it may be difficult or impossible to close the skin even though none has been lost. Furthermore, vascular engorgement may progress to infarction.

Whatever the value of local and systemic antibacterial drugs, the purpose of careful, thorough cleansing of the wound is to remove dirt and the associated bacteria and not to sterilise it. Thus the cleansing agent should be chosen for its cleaning properties rather than an incidental antibacterial effect.

As important as cleaning the wound is the removal of dead fat and muscle. In the patients described only the irreparably damaged and shredded parts of the skin and subcutaneous tissue were removed, but badly damaged muscle was discarded liberally.

With care and patience it has usually been possible to stitch the wound with thin sutures, using fine-toothed forceps or Gillies's hooks. The greater the difficulty in apposing the skin edges the closer the stitches should be, both to each other and to the edges (Case 2, Fig. 7). Any remaining raw surfaces are grafted (Case 3, Fig. 12). Internal fixation is of value in protecting the skin over unstable fractures from tension.

It is our practice not to insert drains but to rely upon careful haemostasis and firm, even pressure bandaging with elevation of the limb.

Occasionally a closed variety of flaying occurs in which the skin remains intact but is extensively torn from its fascial moorings. Massive haemorrhage can distend the enveloping skin sufficiently to arrest its circulation. In Case 10 (Figs. 49 to 55) a combination of both open and closed flaying occurred. A full exploration and deliberate decompression must be considered in such an injury (Stevenson 1941, Slack 1952).

\section{DISCUSSION}

The object of this contribution is to present evidence that initial conservation of undermined skin after severe flaying is often the treatment of choice. It is not our purpose to recommend it as the general method of treatment for milder injuries of a similar nature but to define those circumstances in which it is advantageous.

VOL. 41 B, NO. 4, NOVEMBER 1959 


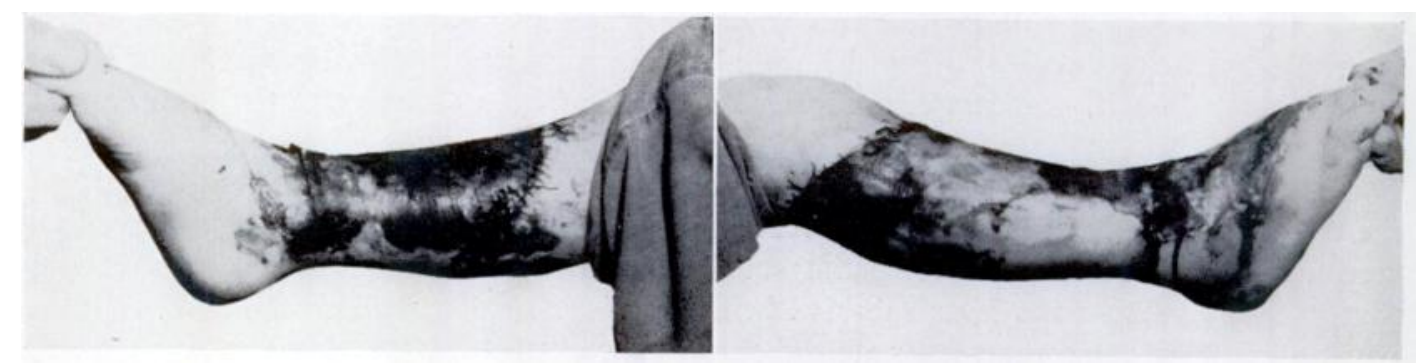

FIG. 42

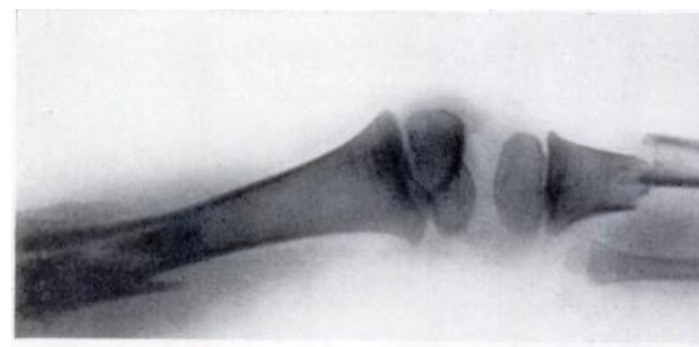

FIG. 44

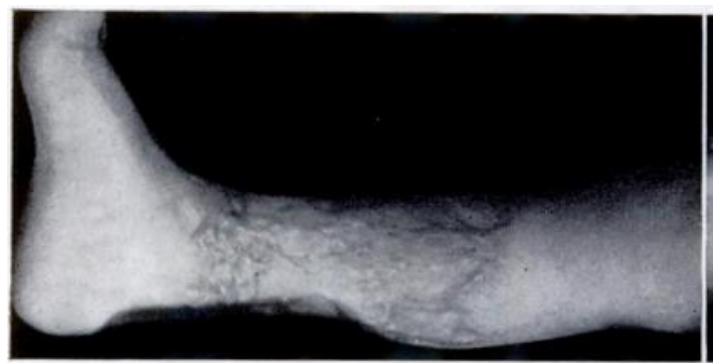

FIG. 46

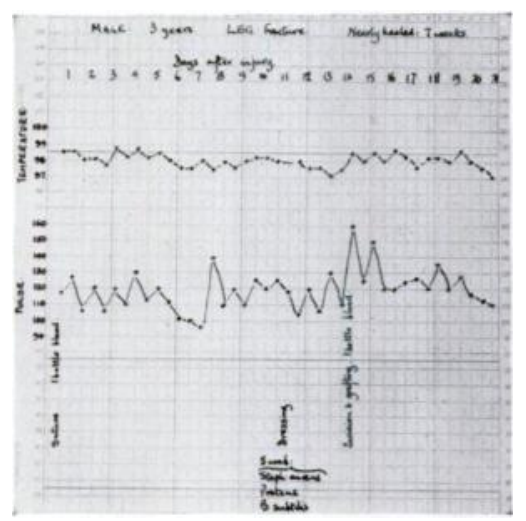

FIG. 48
Fig. 43

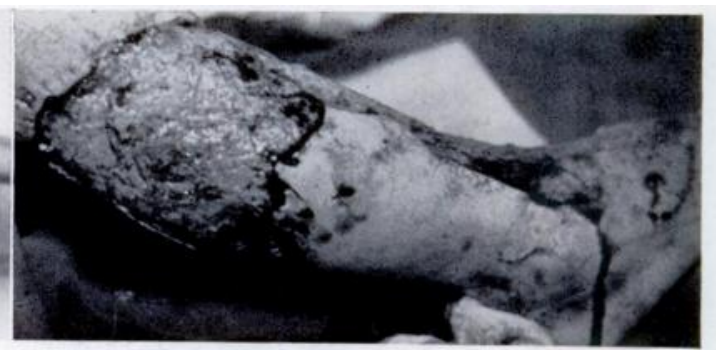

FIG. 45

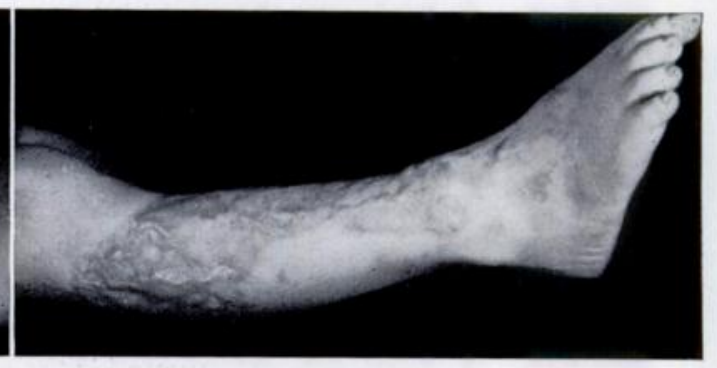

FIG. 47

Figs. 42 to 48

Case 9. Figures 42 and $43-$ Eleven days after injury part of the flaps that have been sutured have died. Figure 44 -The fracture underlying the flaying. Figure 45-The dead skin has been cut away two weeks after the injury, but the underlying fat that was part of the undermined flap has survived and protects the fracture. Figures 46 and $47-$ Six months later. Figure $48-$ The clinical record.

Immediate excision and grafting are recommended with small flaps when their survival is unlikely; it is often convenient to discard the entire flap and even to remove some normal skin if this will leave scars or suture lines more favourably disposed. The type of graft will vary with the site and will depend upon the cosmetic requirements, the likelihood and importance of scarring, the nature and state of the underlying structures and the availability of a suitable donor area. 


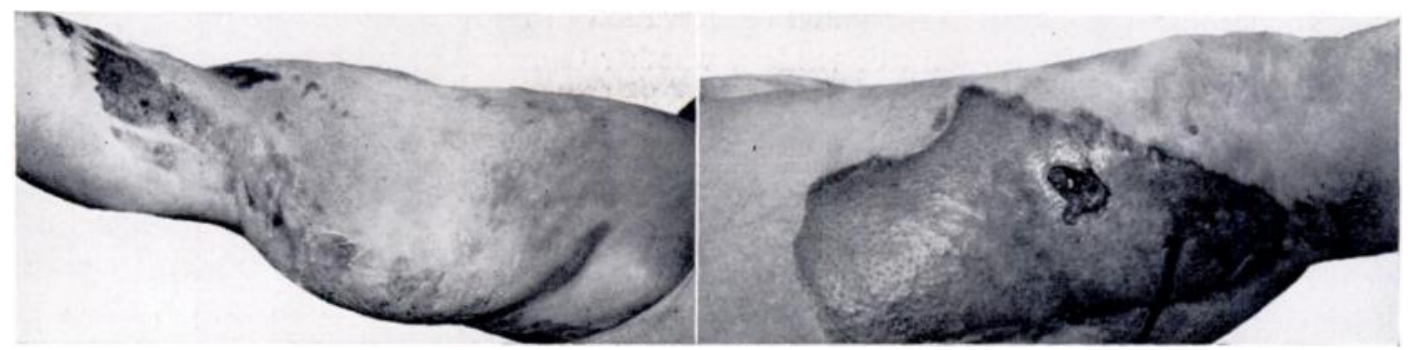

Fig. 49

Fig. 50

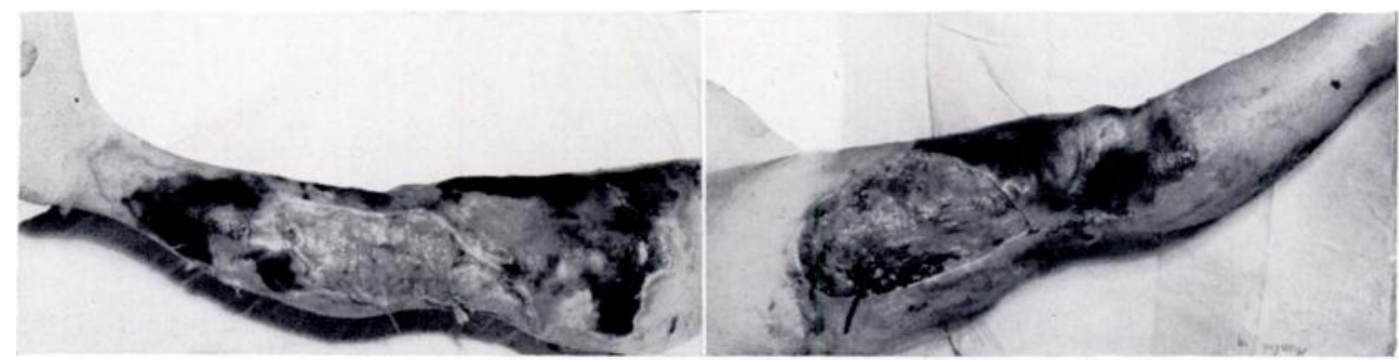

Fig 51

FIG. 52

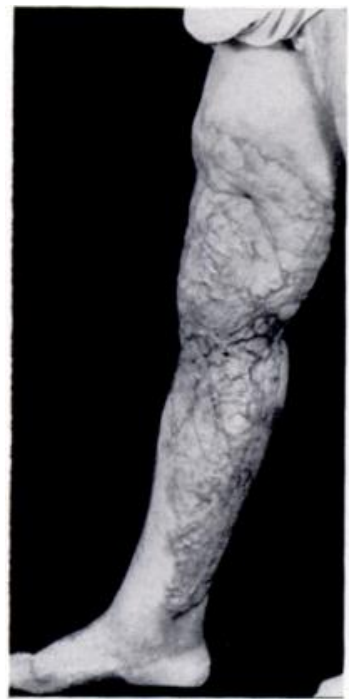

FIG. 53

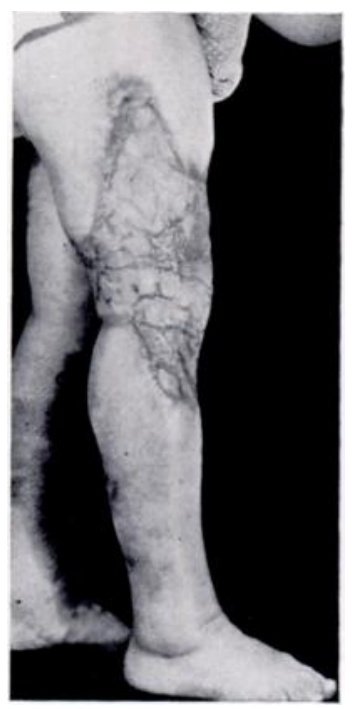

Fig. 54

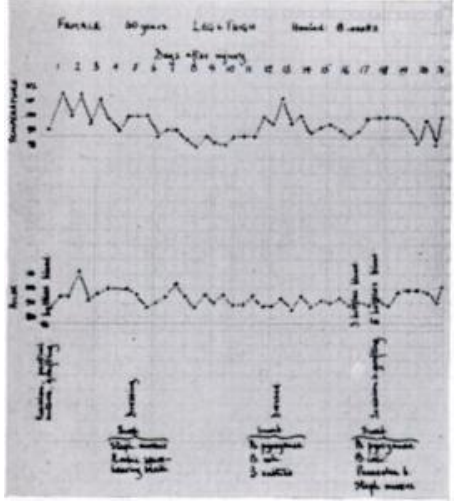

FiG. 55

Case 10-Run-over accident. Figures 49 and 50-Medial and lateral views of leg which had sustained a severe flaying with extensive undermining but only a small breach in the skin. The bulging is due to bleeding under the skin. Figures 51 and 52-Three weeks later. Figures 53 and 54-Four months after injury. Figure 55-The clinical record.

Even extensive flaying may be worth treating by immediate excision and grafting when the grafts can be expected to survive and to compare favourably with the normal skin of the area. It is, however, a taxing operation for surgeon and patient, even when a pneumatic dermatome is used.

Immediate excision may be advisable occasionally when the condition of the patient or the presence of other injuries rules out a lengthy operation; grafting can be done later and until then an antibacterial cream is applied with the dressings.

VOL. 41 B, NO. 4, NOVember 1959 
The strongest justification for initial conservation of injured skin is that it can provide a sound covering for bone, joint or tendon, whether damaged or not, more simply than a graft. The ease and reasonable safety of the method allow it to be used in a wide range of injuries provided that: 1) the patient is treated within a few hours of injury after the blood lost has been made good; 2) the separated skin appears to have some chance of survival; 3) damaged muscle is discarded ruthlessly; 4) the wound, after bleeding has been stopped, is closed with delicate technique, instruments and materials, and the limb supported by firm, even pressure dressings and then elevated; and 5) in the event of discomfort, fever, swelling or smell the responsible surgeon is available to review the treatment. Perhaps the last item is at least as important as the first four.

\section{SUMMARY}

1. The methods of treating flayed limbs are enumerated, with mention of the reasons against conserving the injured skin.

2. The reasons for conserving the injured skin are presented and they are backed by the results in the patients described.

3. The factors that may influence the survival of injured skin are discussed, and the indications for, and methods of, conserving injured skin are described.

We are grateful to Messrs William Heinemann Medical Books Ltd. for permission to publish Figures 10, 11, 49 and 51 .

\section{REFERENCES}

Entin, M. A. (1955): Roller and Wringer Injuries. Plastic and Reconstructive Surgery, 15, 290.

Farmer, A. W. (1939): Treatment of Avulsed Skin Flaps. Annals of Surgery, 110, 951.

Graham, H. F. (1939): Discussion. Annals of Surgery, 110, 959.

Homans, J. (1939): Discussion. Annals of Surgery, 110, 957.

INNIS, C. O. (1957): Treatment of Skin Avulsion Injuries of the Extremities. British Journal of Plastic Surgery, $10,122$.

Mathewson, C., Jun., and Gerber, A. (1947): Surgical Management of Extensive Avulsions of Skin. American Journal of Surgery, N.S. 74, 665.

Mulholland, J. H., and Mahoney, J. H. (1952): Massive Avulsion of Skin. American Journal of Surgery, N.S. 83, 359.

Prendiville, J. B., and Lewis, E. (1955): The Pneumatic-Tyre Torsion Avulsion Injury. British Journal of Surgery, 42, 582.

Schjelderup, H. (1947): Treatment of Skin Avulsion Injuries of the Limbs. Acta Chirurgica Scandinavica, 96, 109.

SlaCk, C. C. (1952): Friction Injuries Following Road Accidents. British Medical Journal, ii, 262.

Stevenson, T. W., Jun. (1941): Principles of Treatment of Avulsion of Skin. Surgical Clinics of North America. 21, 555. 